\title{
Analisis Penempatan Transformator Distribusi Berdasarkan Jatuh Tegangan Di PT PLN(Persero) ULP Malino
}

\author{
Joshua Tiro' ${ }^{1)}$, Ruslan $\mathbf{L}^{2)}$ \\ 1) ,2) Teknik Elektro, Politeknik Negeri Ujung Pandang \\ email : joshuatiro97@gmail.com ${ }^{1)}$,ruslanlausu@gmail.com ${ }^{2)}$
}

\begin{abstract}
Abstrak
Dalam penyaluran energi listrik di mana lokasi pembangkit tenaga listrik berada jauh pada pusat beban memungkinkan terjadinya kerugian yang cukup besar dalam penyaluran energi listrik. Berdasarkan SPLN No. 72 tahun 1987, jatuh tegangan yang diizinkan untuk saluran udara tegangan menengah (SUTM) sebesar 5\%. Penelitian ini bertujuan untuk mengetahui besarnya jatuh tegangan yang terjadi pada penyulang Lanna, PT. PLN (Persero) ULP Malino dan melakukan perbaikan jatuh tegangan tersebut. Penyulang Lanna mempunyai 61 buah gardu distribusi dengan kapasitas yang berbedabeda. Jarak terjauh gardu distribusi dari pusat pembangkit sepanjang 52,995 Km. Metode penelitan dilakukan dengan persamaan atau rumus dan disimulasikan menggunakan Software Digsilent. Hasil penelitian ini menunjukkan bahwa faktorfaktor yang mempengaruhi besarnya jatuh tegangan pada jaringan distribusi adalah arus beban puncak, panjang penghantar, luas penampang penghantar, dan faktor daya. Berdasarkan hasil perhitungan didapatkan bahwa gardu distribusi dengan kode gardu GT.LLN053 mengalami jatuh tegangan sebesar sebesar 1030,16 Volt atau sebesar 5,15\%. Setelah dilakukan perbaikan berupa reposisi gardu distribusi, jatuh tegangan yang terjadi sebesar 956,41 Volt atau sebesar 4,78\%.
\end{abstract}

Kata kunci: Jaringan distribusi, jatuh tegangan, penempatan transformator, Digsilent Power Factory.

\section{PENDAHULUAN}

Listrik merupakan suatu energi yang terbilang cukup banyak dibutuhkan oleh masyarakat sekarang. Dengan melihat perkembangan jumlah penduduk sekarang tentunya kebutuhan energi listrik makin bertambah. Pemanfaatan secara optimal bentuk energi listrik ini harus diikuti dengan sistem distribusi energi listrik yang efisien. Oleh karena itu, kualitas kelistrikan sangatlah penting. Namun dengan adanya keterbatasan penyaluran energi listrik di mana pusat pembangkit yang berada cukup jauh dari pusat beban dapat menyebabkan kerugian yang signifikan seperti jatuh tegangan. Jatuh tegangan dapat menyebabkan kerusakan pada alat-alat kelistrikan karena menurunkan tegangan pada beban sehingga di bawah tegangan nominal yang dibutuhkan. Jatuh tegangan ini tidak bisa dihilangkan, hanya bisa diminimalisir sehingga mencapai batas toleransi yang diizinkan. Dengan adanya kondisi tersebut diperlukan evaluasi dan perencanaan kembali yang memperhatikan kriteria-kriteria perencanaan seperti jatuh tegangan yang diizinkan oleh PLN dan kelangsungan pelayanan listrik sehingga muncul optimasi pada jaringan yang dipakai.

Penyulang Lanna merupakan salah satu penyulang dari pada PT.PLN (Persero) ULP Malino, di mana penyulang ini dilayani oleh Gardu Induk Bili-bili. Dilihat dari lokasi penyulang dengan gardu induk mempunyai jarak yang cukup jauh, hal ini memungkinkan terjadinya jatuh tegangan pada penyulang tersebut. Dengan menghitung nilai jatuh tegangan pada transformator distribusi penyulang Lanna berdasarkan arus beban puncak, panjang penghantar, impedansi penghantar, dan faktor daya dapat diketahui besar jatuh tegangan yang tidak sesuai dengan standar PLN. Maka dengan perhitungan yang tepat akan didapatkan jarak baru dalam penempatan transformator distribusi untuk mendapatkan jatuh tegangan yang cukup kecil dan sesuai dengan standar PLN.

\section{LANDASAN TEORI}

A. Sistem Jaringan Distribusi

Sistem distribusi merupakan bagian dari sistem tenaga listrik. Sistem distribusi ini berguna untuk menyalurkan tenaga listrik dari pembangkit sampai ke konsumen. Klasifikasikan jaringan distribusi primer menurut strukturnya : ${ }^{[1]}$

1. Jaringan radial,

2. jaringan distribusi jarring-jaring,

3. jaringan lingkaran (Loop), dan

4. jaringan spindel.

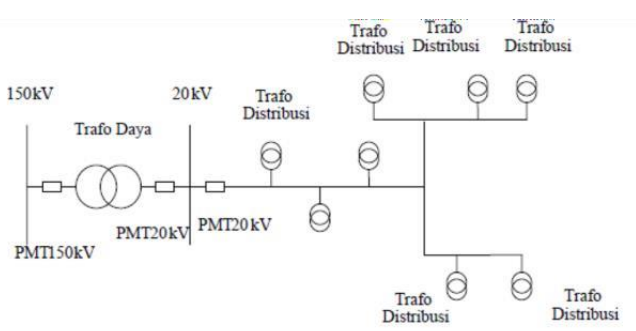

Gambar 2.1 Jaringan Radial 


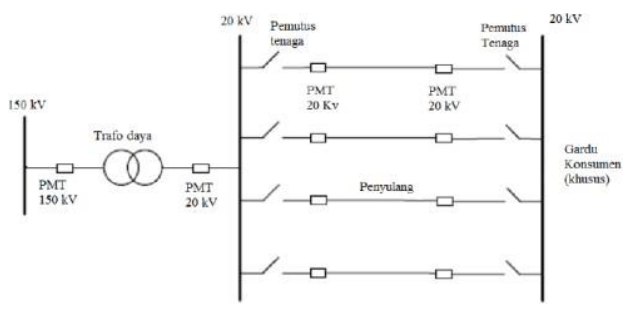

Gambar 2.2 Jaringan distribusi jarring-jaring

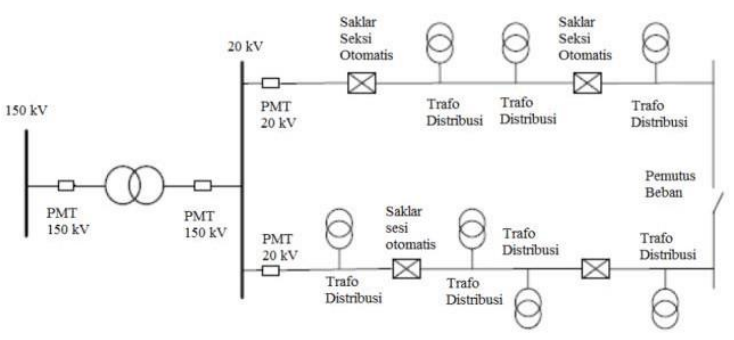

Gambar 2.3 Jaringan lingkaran (Loop)

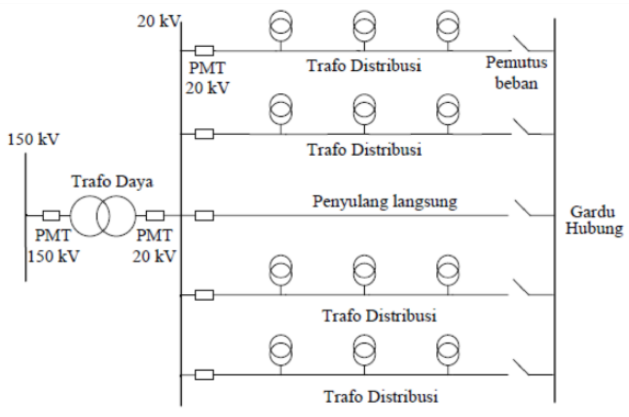

Gambar 2.4 Jaringan Spindel

\section{B. Gardu Distribusi}

Pengertian umum gardu distribusi tenaga listrik yang paling dikenal adalah suatu bangunan gardu listrik yang terdiri dari instalasi perlengkapan hubung bagi tegangan menengah (PHB-TM), transformator distribusi dan perlengkapan hubung bagi tegangan rendah (PHB-TR). Konstruksi gardu distribusi dirancang berdasarkan optimalisasi biaya terhadap maksud dan tujuan penggunaannya yang kadang kala harus disesuaikan dengan peraturan pemerintah daerah setempat ${ }^{[1]}$.

\section{Transformator}

Transformator atau biasa disebut trafo merupakan alat yang dapat memindahkan tenaga listrik antar dua rangkaian listrik melalui induksi elektromagnetik. Dengan kata lain, transformator dapat menaikkan atau menurunkan tegangan listrik. Transformator merupakan alat yang memegang peranan penting dalam sistem distribusi. Penentuan untuk pemilihan dan lokasi transformator sangatlah penting dalam meningkatkan kualitas distribusi energi listrik. Transformator yang paling umum digunakan di Indonesia adalah transformator step-down dengan tegangan $20 \mathrm{kV} / 400 \mathrm{~V}^{[1]}$.

\section{Jatuh Tegangan}

Jatuh tegangan merupakan besarnya tegangan yang hilang pada suatu peralatan. Jatuh tegangan pada saluran tenaga listrik secara umum berbanding lurus dengan panjang saluran dan beban serta berbanding terbalik dengan luas penampang penghantar. Besar jatuh tegangan dapat dinyatakan baik dalam persen atau dalam besaran volt. PT. PLN (Persero) mengatur standar jatuh tegangan yang diperbolehkan dalam SPLN No. 72 tahun 1987, yaitu kurang $5 \%$ dan lebih $10 \%$ pada jaringan tegangan rendah (JTR) sedangkan pada jaringan tegangan menengah (JTM) adalah kurang 5\% dan lebih 5\%. [2]

E. Persamaan yang digunakan dalam analisa

1. Perhitungan arus pada sisi primer transformator ${ }^{[4]}$

Di mana :

$$
\mathrm{I}=\frac{S_{\text {in }}}{\sqrt{3}}
$$

$\mathrm{I}=$ Arus pada sisi primer transformator (Ampere)

$\mathrm{S}_{\mathrm{in}}=$ Besar daya saluran (kVA)

$\mathrm{V}_{\mathrm{L}-\mathrm{L}}=$ Besar tegangan jala-jala (Volt)

2. Perhitungan resistansi total penghantar ${ }^{[3]}$ $\mathrm{R}$ total $=\mathrm{R} \times$ Panjang Kawat Penghantar

3. Perhitungan reaktansi total penghantar ${ }^{[3]}$

$\mathrm{X}_{\mathrm{L}}$ total $=\mathrm{X}_{\mathrm{L}} \mathrm{x}$ Panjang Kawat Penghantar

4. Perhitungan jatuh tegangan ${ }^{[3]}$ untuk 3 fasa :

$$
\Delta \mathrm{V}=\left(\sqrt{3} \times \mathrm{I} \times\left(\mathrm{R} \cos \theta+\mathrm{X}_{\mathrm{L}} \sin \theta\right)\right) \times \mathrm{L}
$$
sedangkan untuk 1 fasa :

$$
\Delta \mathrm{V}=\mathrm{I} \times\left(\mathrm{R} \cos \theta+\mathrm{X}_{\mathrm{L}} \sin \theta\right) \times \mathrm{L}
$$
presentase jatuh tegangan juga dapat dihitung dengan rumus :

$$
\% \mathrm{~V}=\frac{\Delta \mathrm{V}}{V_{S}} \times 100 \%
$$

Di mana :

$\mathrm{V}_{\mathrm{S}}=$ Voltage Sending/Tegangan yang dikirim (Volt)

$\mathrm{R}=$ Resistansi saluran $(\Omega)$

$\mathrm{X}_{\mathrm{L}}=$ Reaktansi saluran $(\Omega)$

$\mathrm{I}=$ Arus pada sisi primer transformator $(\mathrm{A})$

$\mathrm{L}=$ Panjang Saluran $(\mathrm{Km})$

$\operatorname{Cos} \theta=$ Faktor daya

$\Delta \mathrm{V}=$ Jatuh tegangan (Volt)

$\% \mathrm{~V}=$ Persentase jatuh tegangan $(\%)$

5. Perhitungan perbaikan jarak penempatan transformator

$$
\mathrm{L}_{\text {baru }}=\mathrm{V}^{\frac{\mathrm{V}_{\text {diizinkan }} \times \mathrm{L}_{\text {saluran }}}{\Delta \mathrm{V}}}
$$

\footnotetext{
Di mana :

$\mathrm{L}_{\text {baru }}=$ Jarak penempatan transforamtor $(\mathrm{Km})$

$\mathrm{V}_{\text {diizinkan }}=$ Jatuh tegangan yang diizinkan PLN (Volt)

$\mathrm{L}_{\text {saluran }}=$ Panjang saluran $(\mathrm{Km})$
} 


$$
\Delta \mathrm{V}=\text { Jatuh tegangan (Volt) }
$$

F. Digital Simulation and Electrical Network

Digital Simulation and Electrical Network Calculation Program disingkat Digsilent adalah software rekayasa yang berguna untuk analisis sistem tenaga listrik. Dengan menggunakan hanya satu database, yang berisi semua data yang dibutuhkan untuk semua peralatan dalam sistem tenaga misalnya data busbar, data generator, data proteksi, harmonic, data controller. Digsilent dapat dengan mudah mengeksekusi salah satu atau semua fungsi yang tersedia, semua dalam lingkup program yang sama. Beberapa fungsi yang tersedia dalam Software ini adalah analisis aliran daya, perhitungan hubung singkat, analisis harmonic, kordinasi proteksi, perhitungan stabilitas dan jatuh tegangan. ${ }^{[5]}$

\section{METODE PENELITIAN}

Penelitian ini dilakukan oleh beberapa tahap, yang dapat dijabarkan sebagai berikut :

1. Melakukan kegiatan studi literatur dengan mengadakan studi dari buku-buku pustaka, website dan literatur lainnya yang berkaitan dengan masalah yang dibahas dalam penelitian ini.

2. Melakukan observasi atau kunjungan dan pengamatan langsung di PT. PLN (Persero) ULP Malino untuk mengetahui kondisi real dan mendapatkan data-data yang diperlukan dalam penelitian ini.

3. Mengadakan wawancara secara langsung dengan supervisor divisi jaringan distribusi PT. PLN (Persero) ULP Malino atau orang-orang yang mempunyai pengetahuan yang berkaitan dengan penelitian ini.

\section{HASIL DAN PEMBAHASAN}

Penyulang Lanna mempunyai 61 buah gardu distribusi dengan kapasitas yang berbeda-beda. Dari 61 buah gardu distribusi terdapat 17 buah transformator 1 fasa berkapasitas $25 \mathrm{kVA}, 5$ buah transformator 3 fasa berkapasitas $25 \mathrm{kVA}, 4$ buah transformator 1 fasa berkapasitas $50 \mathrm{kVA}, 22$ buah transformator 3 fasa berkapasitas $50 \mathrm{kVA}$ dan 13 buah transformator 3 fasa berkapasitas $100 \mathrm{kVA}$. Pengambilan data beban transformator pada masing-masing gardu distribusi berdasarkan data pengukuran beban puncak dari PT. PLN (Persero) ULP Malino pada bulan Mei tahun 2019. Gardu distribusi yang mengalami jatuh tegangan berdasarkan hasil perhitungan adalah gardu distribusi 1 fasa dengan kode gardu GT.LLN053 dengan panjang saluran 52,995 $\mathrm{Km}$ dan beban sebesar 18,92 kVA. Data pengukuran GT.LLN053 dapat dilihat pada tabel 4.1 berikut.

Tabel 4.1 Data Pengukuran Gardu Distribusi Penyulang Lanna Yang Mengalami Jatuh Tegangan
Kode Gardu

GT.LLN053

\begin{tabular}{lcc}
\hline $\begin{array}{l}\text { Panjang } \\
\text { Penghantar }\end{array}$ & XPLE $240 \mathrm{~mm}^{2}$ & 0,03 \\
$(\mathrm{Km})$ & AAAC $150 \mathrm{~mm}^{2}$ & 45,265 \\
& AAAC $70 \mathrm{~mm}^{2}$ & 7,7 \\
\hline \multirow{2}{*}{ Total Panjang Saluran $(\mathrm{Km})$} & 52,995 \\
\hline \multicolumn{2}{l}{ Total Beban (kVA) } & 18,92
\end{tabular}

Berdasarkan tabel 4.1 maka perhitungan jatuh tegangan pada GT.LLN053 dapat dihitung seperti berikut :

$I=\frac{S_{i n}}{\sqrt{3} V_{L-L}}$

$\mathrm{I}=\frac{18,92}{\sqrt{3} \times 20}$

$\mathrm{I}=0,95 \mathrm{~A}$

$\mathrm{R}$ total $=(0.125 \times 0.03)+(0.2162 \times 45,265)+(0.4608 \times 7,7)$

$$
\begin{aligned}
& =0,00375+9,786+3,548 \\
& =13,34 \mathrm{Ohm} / \mathrm{Km}
\end{aligned}
$$

$\mathrm{X}_{\mathrm{L}}$ total $=(0.097 \times 0.03)+(0,3305 \times 45,265)+(0,3572 \times 7,7)$

$$
\begin{aligned}
& =0,00291+14,96+2,75 \\
& =17,71 \mathrm{Ohm} / \mathrm{Km}
\end{aligned}
$$

$$
\begin{aligned}
\Delta V & =I \times\left(R \cos \theta+\mathrm{X}_{\mathrm{L}} \sin \theta\right) \times \mathrm{L} \\
& =0,95 \times(13,34 \times 0,85+17,71 \times 0,52) \times 52,995 \\
& =0,95 \times(11,33+9,2) \times 52,995 \\
& =1.033,16 \text { Volt } \\
\% \mathrm{~V} & =\frac{\Delta \mathrm{V}}{V_{S}} \times 100 \% \\
& =\frac{1.033,16}{20.000} \times 100 \% \\
& =5.16 \%
\end{aligned}
$$

Dari perhitungan diatas dapat diketahui bahwa jatuh tegangan pada GT.LLN053 melebihi batas yang diizinkan oleh PLN sehingga dibutuhkan perbaikan dalam hal ini adalah perubahan jarak penempatan transformator distribusi tersebut. Dengan menggunakan perhitungan sebagai berikut :

$\mathrm{L}_{\text {baru }}=\frac{\mathrm{V}_{\text {diizinkan }} \times \mathrm{L}_{\text {saluran }}}{\Delta \mathrm{V}}$ 


$$
\begin{aligned}
& =\frac{1.000 \times 52,995}{1.033,16} \\
& =\frac{52.995}{1.033,16} \\
& =51,294 \mathrm{Km}
\end{aligned}
$$

Setelah didapatkan jarak baru sebesar 51,294 Km maka perhitungan yang sama dapat dilakukan untuk mengetahui jatuh tegangan yang terjadi setelah perbaikan dan diperoleh hasil jatuh tegangan sebesar 956,41 Volt atau sebesar $4,78 \%$. Hal ini membuat presentase jatuh tegangan sudah memenuhi standar PLN dan kinerja transformator dapat lebih baik dalam beroperasi.

Perubahan jarak penempatan transformator distribusi ini disimulasikan menggunakan software digsilent sehingga didapatkan hasil jatuh tegangan sebesar 280 Volt atau sebesar 1,4\%. Perbedaan hasil perhitungan dan hasil simulasi ini dapat terjadi karena adanya beberapa data parameter yang kurang lengkap dalam penginputannya pada software digsilent. Gambar simulasi software digsilent dapat dilihat pada gambar 4.1 berikut.

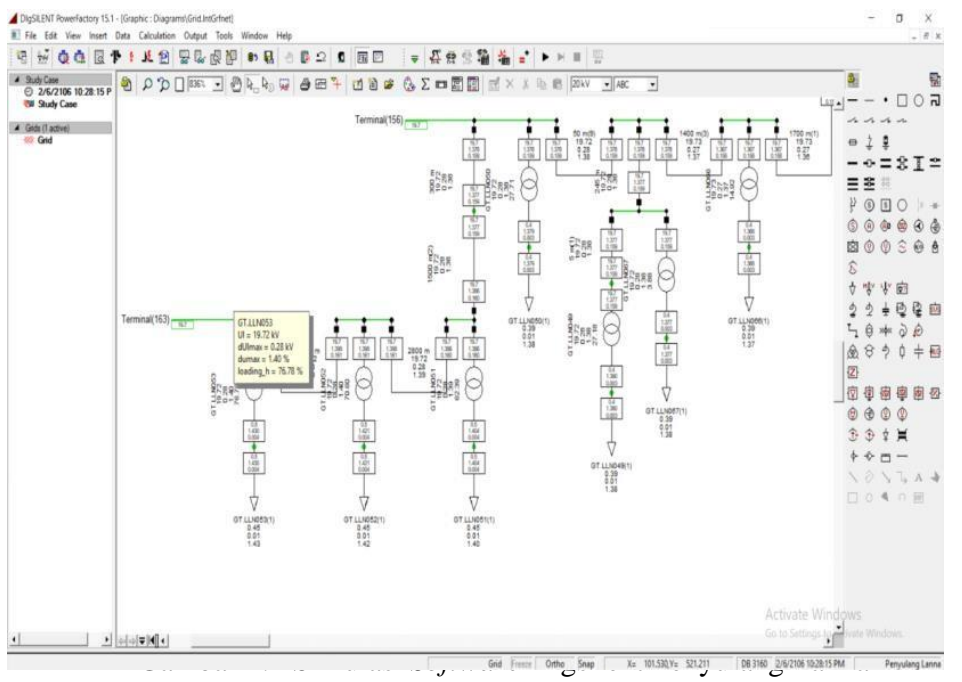

\section{KESIMPULAN}

Jatuh tegangan yang terjadi pada penyulang Lanna dapat dilihat pada gardu distribusi dengan kode gardu GT.LLN053 dengan jatuh tegangan sebesar 1030,16 Volt atau sebesar 5,15\%. Dimana presentase jatuh tegangan ini melebihi dari standar yang ditentukan PLN sebesar $5 \%$. Jatuh tegangan dapat diminimalisir dengan cara perubahan jarak penempatan gardu distribusi (reposisi). Dari hasil analisis perubahan jarak yang dilakukan sebesar $1,551 \mathrm{Km}$ didapatkan nilai jatuh tegangan sebesar 956,41 Volt atau sebesar $4,78 \%$.

Untuk mengoptimalkan kinerja transformator distribusi maka diperlukan penempatan transformator distribusi yang tepat untuk menjaga jatuh tegangan tidak terlalu besar atau melebihi standar yang ditetapkan PLN. Selain itu pemeliharaan yang teratur juga perlu dilaksanakan sehingga kontinuitas pelayanan listrik ke konsumen terjamin.

\section{UCAPAN TERIMA KASIH}

Ucapan terima kasih kami sampaikan kepada Jurusan Teknik Elektro Politeknik Negeri Ujung Pandang, PT. PLN (Persero) ULP Malino dan para dosen pembimbing yang telah membantu dalam pengumpulan data dan pembelajaran serta kepada teman-teman kelas 4B D4 Teknik Listrik 2015 dalam dukungan dan doanya.

\section{REFERENSI}

[1] Suhadi dkk., Teknik Distribusi Tenaga Listrik Jilid 1, Jakarta, Direktorat Pembinaan Sekolah Menengah Kejuruan, Direktorat Jenderal Manajemen Pendidikan Dasar dan Menengah, Departemen Pendidikan Nasional, 2008.

[2] SPLN No.72, Spesifikasi Desain Tegangan Menengah Dan Jaringan Tegangan Rendah, Jakarta, PT. PLN (Persero), 1987

[3] Gonen,T., Electrical Power Distribution System Engineering, New York, McGraw-Hill Book Company, 2008.

[4] William D. Stevenson, J., Elements of Power System Analysis, New York, McGraw-Hill Electrical, 1995.

[5] Gomaringen., Digsilent Power Factory 15 Tutorial, Germany, Heinrich-Hertz-Strabe9, 2013. 